\title{
Investigation of the role of XRCC1 genetic polymorphisms in the development of gliomas in a Chinese population
}

\author{
S.C. Fan' ${ }^{1}$ J.G. Zhou' ${ }^{2}$ and J.Z. Yin ${ }^{1}$ \\ ${ }^{1}$ Department of Neurosurgery, \\ The People's Hospital of Xishuangbana Dai Nationality Autonomous Prefecture, \\ Jinghong, China \\ ${ }^{2}$ Department of Neurosurgery, Peking University People's Hospital, Beijing, \\ China
}

Corresponding author: J.G. Zhou

E-mail: zhoujingrue@163.com

Genet. Mol. Res. 15 (3): gmr.15038268

Received December 14, 2015

Accepted February 11, 2016

Published August 26, 2016

DOI http://dx.doi.org/10.4238/gmr.15038268

Copyright (C) 2016 The Authors. This is an open-access article distributed under the terms of the Creative Commons Attribution ShareAlike (CC BY-SA) 4.0 License.

\begin{abstract}
We conducted a study in a Chinese Han population to investigate the role of XRCC1 gene polymorphisms (Arg399Gln and Arg 194Trp) with a risk of susceptibility to gliomas. Samples from 115 patients with gliomas and 228 control subjects were consecutively collected between March 2012 and December 2014. Genotype analysis of XRCC1 Arg399Gln and Arg194Trp was performed using polymerase chain reaction-restriction fragment length polymorphism assay. All the analyses were performed using the SPSS 17.0 software package. We observed that the XRCC1 Arg399Gln and Arg194Trp genotype frequencies conformed to the Hardy-Weinberg equilibrium. We observed that the Trp/Trp genotype of XRCC1 Arg194Trp was associated with an increased risk of glioma when compared to the
\end{abstract}


wild-type genotype (odds ratio $(\mathrm{OR})=2.14,95 \%$ confidence interval $(\mathrm{CI})=1.14-3.86, \mathrm{P}=0.03)$. In the dominant model, we found that the Arg/Trp + Trp/Trp genotype of XRCC1 Arg194Trp could significantly elevate the susceptibility of developing glioma $(\mathrm{OR}=1.79,95 \% \mathrm{CI}=$ 1.07-0.94). However, we observed that the XRCC1 Arg399Gln genetic polymorphism did not influence the risk of glioma. In summary, we suggest that the XRCC1 Arg194Trp genetic polymorphism could be a predictive biomarker for the susceptibility to glioma in a Chinese population.

Key words: XRCC1; Arg399Gln; Arg194Trp; Polymorphism; Glioma; Chinese population

\section{INTRODUCTION}

Malignant glioma is the most frequent form of primary brain tumors and is always accompanied by a poor prognosis. The etiology of gliomas remains poorly understood. Previous epidemiologic studies have reported that many environmental and lifestyle factors contribute to the development of gliomas (Ohgaki and Kleihues, 2005). However, increasing evidence has indicated that hereditary factors may be involved in modifying glioma susceptibility (Kinnersley et al., 2015). Genetic studies demonstrated that several genetic factors may play an important role in the development of gliomas, such as CCDC26, CDKN2BAS, RTEL1, and TERT genes (Adel Fahmideh et al., 2015; Wang et al., 2015a).

Polymorphisms in DNA repair genes leading to variation of DNA repair efficiency may be correlated with development of several kinds of cancers (De Gobbi et al., 2006; Nothnagel et al., 2009). XRCC1 is located on chromosome 19q13.2-19q13.3, is $33 \mathrm{~kb}$ in length, and contains 17 exons. The XRCC1 gene can combine with many other components and play an important role in facilitating base excision repair and single-strand break repair processes. Previous studies have reported that XRCC1 gene polymorphisms contribute to the development of cancers, such as lung, colorectal, breast, and ovarian cancers (Guo et al., 2015; Malisic et al., 2015; Nissar et al., 2015; Wang et al., 2015b). Recently, several epidemiologic studies have assessed the association between XRCC1 gene polymorphisms and susceptibility to glioma, but their findings are inconclusive (Feng et al., 2014; Li et al., 2014; Rodriguez-Hernandez et al., 2014; Wang et al., 2015a). In our study, we examined a Chinese Han population and investigated the role of XRCC1 gene polymorphisms (Arg399Gln and Arg194Trp) with a risk for susceptibility to gliomas.

\section{MATERIAL AND METHODS}

\section{Patients}

Here, a hospital-based case-control study was performed. Samples from 115 patients with gliomas and 228 control subjects were consecutively collected from the People's Hospital of Xishuangbana Dai Nationality Autonomous Prefecture between March 2012 and December 2014. All the patients were newly diagnosed and confirmed to have gliomas with pathological examination. All the patients with gliomas were confirmed to be without history of other

Genetics and Molecular Research 15 (3): gmr.15038268 
malignant tumors and prior chemotherapy or radiochemotherapy.

The control subjects were enrolled from amongst individuals who came to receive regular health check-up examinations. All the patients with gliomas and the control subjects were of Han Chinese ethnicity. The control subjects were confirmed to be without malignant tumors, infectious diseases, or serious endocrine, metabolic, or nutritional disorders.

The demographic and lifestyle data were collected from a structured questionnaire or medical records, including age, gender, exposure to ionizing radiation, tobacco smoking, alcohol consumption, and family history of cancer. All the patients with gliomas and the control subjects gave their informed consent before enrolling in this study. This study was approved by the Ethics Committee of the People's Hospital of Xishuangbana Dai Nationality Autonomous Prefecture.

\section{Genotyping methods}

Five milliliters of peripheral blood was collected from patients with gliomas and the control subjects after recruitment into this study. The blood samples were stored at $-20^{\circ} \mathrm{C}$ until use. The DNA extraction was performed using the TIANGEN blood mini kit (TIANGEN Co. Limited, Beijing, China). DNA $(1 \mu \mathrm{L})$ was used as the template for each polymerase chain reaction (PCR) cycle. Genotype analysis of XRCC1 Arg399Gln and Arg194Trp was performed using PCR-restriction fragment length polymorphism (PCR-RFLP) assay. The primers, restriction enzymes, and product sizes are shown in Table 1. The PCR products were digested with restriction enzymes, analyzed using electrophoresis on a $2 \%$ agarose gel, and observed under UV light.

Table 1. Primers, restriction enzymes, and product sizes of XRCC1 Arg399Gln and Arg194Trp genes.

\begin{tabular}{l|l|l|l|c}
\hline XRCC1 & SNP & Primers (5'-3') & Restriction enzyme & PCR product (bp) \\
\hline Arg399Gln & rs25487 & $\begin{array}{l}\text { TTGTGCTTTCTCTGTGTCCA (forward) } \\
\text { TCCTCCAGCCTTTACTGATA (reverse) }\end{array}$ & MspI & 615 \\
\hline Arg194Trp & rs1799782 & $\begin{array}{l}\text { GTGAAGGAGGAGGATGAGAGC (forward) } \\
\text { CCCCAGCCCCCTCTACCCT (reverse) }\end{array}$ & PvuII & 160 \\
\hline
\end{tabular}

\section{Statistical analysis}

The categorical and quantitative data between the patients with gliomas and control subjects were compared using the Student $t$-test or the chi-square $\left(\chi^{2}\right)$ test. Before performing the association study, the Hardy-Weinberg equilibrium (HWE) for any deviation from expected allele frequencies was tested by using the $\chi^{2}$ test. Genotype frequencies between the patients with gliomas and control subjects were compared using the $\chi^{2}$ test. The odds ratios (ORs) and 95\% confidence intervals (CIs) were calculated using unconditional logistic regression analysis and the results were adjusted for potential confounding factors. Three genetic models, including codominant, dominant, and recessive, were performed to assess the association between XRCC1 Arg399Gln and Arg 194Trp and glioma risk. All the analysis was performed using the SPSS 17.0 software package (SPSS Inc., Chicago, IL, USA). All P values used in this study were two-sided. A $\mathrm{P}$ value $<0.05$ at $95 \% \mathrm{CI}$ was taken as statistically significant.

Genetics and Molecular Research 15 (3): gmr.15038268 


\section{RESULTS}

The mean age of patients and control subjects was $48.53 \pm 10.34$ and $46.65 \pm 11.60$ years, respectively (Table 2). Patients with gliomas were comparable with control subjects in terms of age, gender, tobacco smoking, alcohol consumption, and family history of cancer. However, a significant difference was observed between patients and controls with respect to exposure to ionizing radiation $\left(\chi^{2}=9.36, \mathrm{P}=0.002\right)$.

Table 2. Demographic characteristics of patients with gliomas and control subjects.

\begin{tabular}{|c|c|c|c|c|c|c|}
\hline Variables & Patients $(\mathrm{N}=115)$ & $\%$ & Controls $(\mathrm{N}=228)$ & $\%$ & $t$-test or $\chi^{2}$ test & $\mathrm{P}$ value \\
\hline Age (years) & $48.53 \pm 10.34$ & & $46.65 \pm 11.60$ & & & \\
\hline \multicolumn{7}{|l|}{ Gender } \\
\hline Female & 49 & 42.61 & 104 & 45.61 & & \\
\hline Male & 66 & 57.39 & 124 & 54.39 & 0.28 & 0.60 \\
\hline \multicolumn{7}{|c|}{ Tobacco smoking } \\
\hline No & 37 & 32.17 & 69 & 30.26 & & \\
\hline Yes & 78 & 67.83 & 159 & 69.74 & 0.13 & 0.72 \\
\hline \multicolumn{7}{|c|}{ Alcohol consumption } \\
\hline No & 29 & 25.22 & 50 & 21.93 & & \\
\hline Yes & 86 & 74.78 & 178 & 78.07 & 0.47 & 0.50 \\
\hline \multicolumn{7}{|c|}{ Family history of cancer } \\
\hline No & 106 & 92.17 & 212 & 92.98 & & \\
\hline Yes & 9 & 7.83 & 16 & 7.02 & 0.07 & 0.79 \\
\hline \multicolumn{7}{|c|}{ Exposure to ionizing radiation } \\
\hline No & 12 & 10.43 & 6 & 2.63 & & \\
\hline Yes & 103 & 89.57 & 222 & 97.37 & 9.36 & 0.002 \\
\hline
\end{tabular}

The distributions of XRCC1 Arg399Gln and Arg194Trp genes are presented in Table 3. For the XRCC1 Arg399Gln polymorphism, 42 (36.52\%), 51 (44.35\%), and 22 (19.13\%) glioma patients harbored the Arg/Arg, Arg/Gln, and Gln/Gln genotypes, respectively. For the control subjects, 92 (40.35\%), 99 (43.42\%), and $37(16.23 \%)$ harbored the Arg/Arg, Arg/Gln, and Gln/Gln genotypes, respectively. For the XRCC1 Arg194Trp polymorphism, $31(26.96 \%), 58(50.43 \%)$, and $26(22.61 \%)$ glioma patients harbored the Arg/Arg, Arg/Trp, and Trp/Trp genotypes, respectively. For the control subjects, 82 (35.96\%), 109 (47.81\%), and 37 (16.23\%) harbored the Arg/Arg, Arg/Trp, and Trp/ Trp genotypes, respectively. There was no significant difference found in the genotype frequencies of XRCC1 Arg399Gln $\left(\chi^{2}=0.68, \mathrm{P}=0.71\right)$ and $\operatorname{Arg} 194 \operatorname{Trp}\left(\chi^{2}=3.69, \mathrm{P}=\right.$ $0.16)$ between glioma patients and controls. We observed that XRCC1 Arg399Gln and Arg194Trp genotype frequencies conformed to the HWE.

Table 3. Genotype distributions of XRCC1 Arg399Gln and Arg194Trp genes.

\begin{tabular}{|c|c|c|c|c|c|c|c|c|}
\hline \multirow[t]{2}{*}{ XRCC1 } & \multirow[t]{2}{*}{ Patients $(\mathrm{N}=115)$} & \multirow[t]{2}{*}{$\%$} & \multirow[t]{2}{*}{ Controls $(\mathrm{N}=228)$} & \multirow[t]{2}{*}{$\%$} & \multirow[t]{2}{*}{$\chi^{2}$ test } & \multirow[t]{2}{*}{$P$ value } & \multicolumn{2}{|c|}{$\mathrm{P}$ for $\mathrm{HWE}$} \\
\hline & & & & & & & Patients & Controls \\
\hline Arg399Gln & 42 & 36.52 & 92 & 40.35 & & & & \\
\hline Arg/Arg & 51 & 44.35 & 99 & 43.42 & & & & \\
\hline Arg/Gln & 22 & 19.13 & 37 & 16.23 & 0.68 & 0.71 & 0.36 & 0.24 \\
\hline \multicolumn{9}{|l|}{ Gln/Gln } \\
\hline \multicolumn{9}{|l|}{ Arg194Trp } \\
\hline Arg/Arg & 31 & 26.96 & 82 & 35.96 & & & & \\
\hline Arg/Trp & 58 & 50.43 & 109 & 47.81 & & & & \\
\hline $\operatorname{Trp} / \operatorname{Trp}$ & 26 & 22.61 & 37 & 16.23 & 3.69 & 0.16 & 0.91 & 0.94 \\
\hline
\end{tabular}

Genetics and Molecular Research 15 (3): gmr.15038268 
We analyzed the correlation between XRCC1 Arg399Gln and Arg194Trp genetic polymorphisms and glioma risk using codominant, dominant, and recessive models with unconditional multivariate logistic regression analysis (Table 4). We observed that the Trp/Trp genotype of XRCC1 Arg194Trp was associated with an increased risk of glioma when compared to the wild-type genotype $(\mathrm{OR}=2.14,95 \% \mathrm{CI}=1.14-3.86, \mathrm{P}=0.03)$. In a dominant model, we found that the Arg/Trp + Trp/Trp genotype could significantly elevate the susceptibility of developing glioma $(\mathrm{OR}=1.79,95 \% \mathrm{CI}=1.07-0.94)$. However, we observed that XRCC1 Arg399Gln genetic polymorphisms could not influence the risk of glioma.

Table 4. Association between XRCC1 Arg399Gln and Arg194Trp genetic polymorphisms and susceptibility to glioma.

\begin{tabular}{|c|c|c|c|c|c|c|}
\hline $\mathrm{XRCC1}$ & Patients & $\%$ & Controls & $\%$ & OR $(95 \% \mathrm{CI})$ & $\mathrm{P}$ value \\
\hline \multicolumn{7}{|l|}{ Arg399Gln } \\
\hline \multicolumn{7}{|l|}{ Codominant } \\
\hline Arg/Arg & 42 & 36.52 & 92 & 40.35 & 1.0 (Ref.) & - \\
\hline Arg/Gln & 51 & 44.35 & 99 & 43.42 & $1.13(0.67-1.92)$ & 0.63 \\
\hline $\mathrm{G} \ln / \mathrm{G} \ln$ & 22 & 19.13 & 37 & 16.23 & $1.30(0.65-2.59)$ & 0.42 \\
\hline \multicolumn{7}{|l|}{ Dominant } \\
\hline Arg/Arg & 42 & 36.52 & 92 & 40.35 & 1.0 (Ref.) & - \\
\hline $\mathrm{Arg} / \mathrm{Gln}+\mathrm{Gln} / \mathrm{Gln}$ & 73 & 63.48 & 136 & 59.65 & $1.18(0.72-1.92)$ & 0.49 \\
\hline \multicolumn{7}{|l|}{ Recessive } \\
\hline Arg/Arg+ Arg/Gln & 93 & 80.87 & 191 & 83.77 & 1.0 (Ref.) & - \\
\hline $\mathrm{G} \ln / \mathrm{Gln}$ & 22 & 19.13 & 37 & 16.23 & $1.22(0.65-2.26)$ & 0.50 \\
\hline \multicolumn{7}{|l|}{ Arg194Trp } \\
\hline \multicolumn{7}{|l|}{ Codominant } \\
\hline Arg/Arg & 31 & 26.96 & 82 & 35.96 & 1.0 (Ref.) & - \\
\hline Arg/Trp & 58 & 50.43 & 109 & 47.81 & $1.41(0.81-2.46)$ & 0.20 \\
\hline Trp/Trp & 26 & 22.61 & 37 & 16.23 & $2.14(1.14-3.86)$ & 0.03 \\
\hline \multicolumn{7}{|l|}{ Dominant } \\
\hline Arg/Arg & 31 & 26.96 & 82 & 35.96 & 1.0 (Ref.) & - \\
\hline Arg/Trp +Trp/Trp & 84 & 73.04 & 146 & 64.04 & $1.79(1.07-.94)$ & 0.04 \\
\hline \multicolumn{7}{|l|}{ Recessive } \\
\hline Arg/Arg + Arg/Trp & 89 & 77.39 & 191 & 83.77 & 1.0 (Ref.) & - \\
\hline Trp/Trp & 26 & 22.61 & 37 & 16.23 & $1.57(0.93-2.60)$ & 0.09 \\
\hline
\end{tabular}

\section{DISCUSSION}

We conducted a hospital clinical study to investigate the association between $X R C C 1$ Arg399Gln and Arg194Trp genetic polymorphisms and susceptibility to glioma in a Chinese population, and we observed that individuals harboring the Trp/Trp and Arg/Trp + Trp/Trp genotypes were at an increased risk of glioma compared to individuals harboring the wildtype genotype. However, no significant correlation was found between the XRCC1 Arg399Gln polymorphism and susceptibility to gliomas.

Previous studies have reported that $X R C C 1$ genetic polymorphisms may influence the development of several kinds of cancers, such as lung, colorectal, ovarian, thyroid, and esophageal squamous cell cancers (Han et al., 2015; Malisic et al., 2015; Nissar et al., 2015; Wang et al., 2015b,c,d; Yun et al., 2015). Wang et al. (2015b) conducted a study in a Chinese population and reported that the rs25487 genetic polymorphism contributed to the risk of development of lung cancer. Han et al. (2015) conducted a study in a Chinese population and revealed that the XRCC1 Arg399Gln polymorphism correlated with an increased risk of non-small-cell lung cancer. Nissar et al. (2015) performed a study in an Indian population 
and suggested that the XRCC1 Arg194Trp polymorphism modulated the risk of developing colorectal cancer. Malisic et al. (2015) revealed that the XRCC1 Arg399Gln polymorphism could be a predictive biomarker for developing ovarian cancer. However, Yun et al. (2015) did not find a significant association between the XRCC1 Arg399Gln polymorphism and development of esophageal squamous cell carcinoma in a Chinese population.

Epidemiologic studies have reported the association of XRCC1 genetic polymorphisms and susceptibility to glioma in a Chinese population, but their findings are inconclusive (Luo et al., 2013; Wang et al., 2013; Xu et al., 2014; Zhu et al., 2014). Luo et al. (2013) conducted a study in a Chinese population and showed that the XRCC1 Arg399Gln and Arg194Trp polymorphisms could increase the risk of gliomas. Wang et al. (2013) suggested that the XRCC1 Arg399Gln polymorphism was associated with a significantly increased risk for glioma in a Chinese population. Xu et al. (2014) indicated that the XRCC1 Arg399Gln and Arg194Trp genetic variations had a higher risk of glioma in a Chinese population. Zhu et al. (2014) conducted a meta-analysis and reported that the XRCC1 Arg399Gln polymorphism may affect the risk of glioma. However, our study only revealed a significant association of the XRCC1 Arg194Trp polymorphism with glioma risk, but the XRCC1 Arg399Gln polymorphism had no effective role in the risk of this cancer. The discrepancies of the above-mentioned studies may be caused by different ethnicities and sample size.

In summary, we suggest that the XRCC1 Arg194Trp genetic polymorphism could be a predictive biomarker for the susceptibility to glioma in a Chinese population. Further large-scale studies are greatly warranted to confirm the association between XRCC1 genetic polymorphisms and risk of development of glioma.

\section{Conflicts of interest}

The authors declare no conflict of interest.

\section{ACKNOWLEDGMENTS}

We thank the nurses in the People's Hospital of Xishuangbana Dai Nationality Autonomous Prefecture who helped us to collect blood samples from the study subjects.

\section{REFERENCES}

Adel Fahmideh M, Lavebratt C, Schüz J, Röösli M, et al. (2015). CCDC26, CDKN2BAS, RTEL1 and TERT Polymorphisms in pediatric brain tumor susceptibility. Carcinogenesis 36: 876-882. http://dx.doi.org/10.1093/carcin/bgv074

De Gobbi M, Viprakasit V, Hughes JR, Fisher C, et al. (2006). A regulatory SNP causes a human genetic disease by creating a new transcriptional promoter. Science 312: 1215-1217.

Feng X, Miao G, Han Y, Xu Y, et al. (2014). Glioma risks associate with genetic polymorphisms of XRCC1 gene in Chinese population. J. Cell. Biochem. 115: 1122-1127. http://dx.doi.org/10.1002/jcb.24753

Guo S, Mao X and Ming L (2015). XRCC1 Arg399Gln polymorphism is not associated with breast cancer in Chinese. Int. J. Clin. Exp. Med. 8: 10429-10436.

Han JC, Zhang YJ and Li XD (2015). Association between polymorphisms in the XRCC1 gene and the risk of non-small cell lung cancer. Genet. Mol. Res. 14: 12888-12893. http://dx.doi.org/10.4238/2015.October.21.9

Kinnersley B, Mitchell JS, Gousias K, Schramm J, et al. (2015). Quantifying the heritability of glioma using genome-wide complex trait analysis. Sci. Rep. 5: 17267.http://dx.doi.org/10.1038/srep17267.

Li J, Qu Q, Qu J, Luo WM, et al. (2014). Association between XRCC1 polymorphisms and glioma risk among Chinese population. Med. Oncol. 31: 186.http://dx.doi.org/10.1007/s12032-014-0186-2

Genetics and Molecular Research 15 (3): gmr.15038268 
Luo KQ, Mu SQ, Wu ZX, Shi YN, et al. (2013). Polymorphisms in DNA repair genes and risk of glioma and meningioma. Asian Pac. J. Cancer Prev. 14: 449-452. http://dx.doi.org/10.7314/APJCP.2013.14.1.449

Malisic EJ, Krivokuca AM, Boljevic IZ and Jankovic RN (2015). Impact of RAD51 G135C and XRCC1 Arg399Gln polymorphisms on ovarian carcinoma risk in Serbian women. Cancer Biomark. 15: 685-691. http://dx.doi. org/10.3233/CBM-150509

Nissar S, Sameer AS, Rasool R, Chowdri NA, et al. (2015). Polymorphism of the DNA repair gene XRCC1 (Arg194Trp) and its role in colorectal cancer in Kashmiri population: a case control study. Asian Pac. J. Cancer Prev. 16: 63856390. http://dx.doi.org/10.7314/APJCP.2015.16.15.6385

Nothnagel M, Ellinghaus D, Schreiber S, Krawczak M, et al. (2009). A comprehensive evaluation of SNP genotype imputation. Hum. Genet. 125: 163-171.

Ohgaki H and Kleihues P (2005). Epidemiology and etiology of gliomas. Acta Neuropathol. 109: 93-108. http://dx.doi. org/10.1007/s00401-005-0991-y

Rodriguez-Hernandez I, Perdomo S, Santos-Briz A, Garcia JL, et al. (2014). Analysis of DNA repair gene polymorphisms in glioblastoma. Gene 536: 79-83.http://dx.doi.org/10.1016/j.gene.2013.11.077

Wang L, Jiang YQ, Zhou MD and Jiang Z (2015a). Association between XRCC1 Arg399Gln polymorphism and glioma risk in a Chinese population: a case-control study. Int. J. Clin. Exp. Med. 8: 10026-10030.

Wang X, Ma KW, Zhao YG, Wang GJ, et al. (2015b). XRCC1 rs25487 polymorphism is associated with lung cancer risk in epidemiologically susceptible Chinese people. Genet. Mol. Res. 14: 15530-15538.http://dx.doi.org/10.4238/2015. December.1.3

Wang X, Zhang K, Liu X, Liu B, et al. (2015c). Association between XRCC1 and XRCC3 gene polymorphisms and risk of thyroid cancer. Int. J. Clin. Exp. Pathol. 8: 3160-3167.

Wang YX, Fan K, Tao DB and Dong X (2013). Association between genetic polymorphism of xrec1 gene and risk of Glioma in? Chinese population. Asian Pac. J. Cancer Prev. 14: 5957-5960.http://dx.doi.org/10.7314/APJCP.2013.14.10.5957

Wang Z, Rajaraman P, Melin BS, Chung CC, et al. (2015d). Further confirmation of germline glioma risk variant rs78378222 in TP53 and its implication in tumor tissues via integrative analysis of TCGA data. Hum. Mutat. 36 : 684-688. http://dx.doi.org/10.1002/humu.22799

Xu G, Wang M, Xie W and Bai X (2014). Three polymorphisms of DNA repair gene XRCC1 and the risk of glioma: a case-control study in northwest China. Tumour Biol. 35: 1389-1395.http://dx.doi.org/10.1007/s13277-013-1191-3

Yun YX, Dai LP, Wang P, Wang KJ, et al. (2015). Association of polymorphisms in X-ray repair cross complementing 1 gene and risk of esophageal squamous cell carcinoma in a Chinese population. BioMed Res. Int. 2015: 509215.http:// dx.doi.org/10.1155/2015/509215

Zhu W, Yao J, Li Y and Xu B (2014). Assessment of the association between XRCC1 Arg399Gln polymorphism and glioma susceptibility. Tumour Biol. 35: 3061-3066. http://dx.doi.org/10.1007/s13277-013-1397-4

Genetics and Molecular Research 15 (3): gmr.15038268 